\title{
Teachers' Mental Health and Self-Reported Coping Strategies During the COVID-19 Pandemic in Ecuador: A Mixed-Methods Study
}

\section{Paula Hidalgo-Andrade (ID) Carlos Hermosa-Bosano (D) Clara Paz}

Escuela de Psicología, Universidad de Las Américas, Quito, Ecuador
Correspondence: Clara Paz Redondel del Ciclista, Antigua Vía a Nayón, Quito, 170124, Ecuador Tel +5932398 1000 Ext. 2518

Email clara.paz@udla.edu.ec
Purpose: This study assessed the psychological distress, life satisfaction, and perceived stress of Ecuadorian teachers who adopted online learning in response to the COVID-19 pandemic. It also aimed to qualitatively report the coping strategies used to maintain their mental health and well-being.

Methods: A web-based cross-sectional survey was conducted from June to mid-August 2020.

Results: In total, 394 teachers completed the questionnaire, and from those, 320 also completed an optional open-ended question included in the survey. More than half of the participants reported taking care of children under 11 years and/or adults over 65 years. At the time of the study, most of the participants were teaching in higher education settings. Age was significantly correlated with all the psychological variables, females presented higher levels of perceived stress, and teachers with home care responsibilities presented higher psychological distress as well as perceived stress. Teachers who had previous training and experience with online teaching presented lower levels of distress, perceived stress as well as higher levels of life satisfaction. The most used coping strategies included seeking social support, exercising, and engaging in leisure activities.

Conclusion: The results provide useful information to help develop initiatives that promote teacher well-being. Future studies should consider using a more diverse sample and dedicate attention to work-family conflicts as well as social and structural inequalities that may have a toll on teachers' mental health and performance.

Keywords: education, lockdown, online teaching, psychological distress, self-care, stress

\section{Plain Language Summary}

Since COVID-19 became a pandemic, the field of education has experienced drastic changes including the adoption of remote learning. As a result, teachers have had to continue their job amid a series of circumstances and stressors that may have had a toll on their mental health state. This study sought to understand the emotional well-being and coping strategies used by Ecuadorian teachers who completed an online survey in the midst of the COVID-19 global health emergency. Results indicate that:

- participants who had previous training and experience with online teaching presented lower levels of emotional distress as well as higher levels of life satisfaction,

- the most common coping strategies included seeking social support, exercising, and participating in leisure activities. 
This study exposes the need to deepen our knowledge about teachers' experiences and challenges related to the pandemic. It also suggests the need to develop re institutional support mechanisms to ensure their well-being.

\section{Introduction}

The rapid spread of the Coronavirus disease 2019 (COVID-19) has resulted in a global pandemic that has claimed millions of lives thus far. ${ }^{1}$ This unprecedented health emergency has taken a toll on the economy of millions of individuals and families and, to date, continues to test the capabilities of health systems worldwide. The pandemic has also impacted the educational systems of many countries as it forced educational institutions to adopt online remote learning to continue offering their services. This rapid adoption of Information and Communications Technologies (ICTs) as the primary resource in the teaching-learning process has evidenced several challenges for students and teachers, ${ }^{2}$ including tech-illiteracy and access to adequate technological infrastructure, ${ }^{3,4}$ and are expected to aggravate the previously existing learning disparities across regions. ${ }^{5}$

On an individual level, the pandemic has brought a series of stressors to the daily lives of people, including fears of death and infection, the loss of loved ones, confinement and mobility restrictions, increased home and care responsibilities, economic instability, among others. $^{6-11}$ As a result of the pandemic and the series of prevention and control measures taken, there has been an increase in the number of symptoms and signs of stress, anxiety, and depression among the general population and other specific subgroups including people in the epidemiological fence, ${ }^{12,13}$ medical staff, ${ }^{14-16}$ and mental health professionals. $^{17,18}$

There is also increasing evidence that suggests that the pandemic has had a significant impact on the well-being of teachers and students. In China, a study conducted by Huang \& $\mathrm{Zhao}^{19}$ found that $35.1 \%$ of teachers and students presented moderate symptoms of anxiety and $21 \%$ moderate symptoms of depression, whereas in Germany, teachers experienced a medium-to-high amount of stress during lockdown. ${ }^{17}$ In the United Kingdom (UK), teachers reported high levels of anxiety ${ }^{20}$ and, in Chile, the pandemic negatively affected teachers' quality of life, especially among women and younger teachers. ${ }^{18}$

Changes in the mental health condition of teachers are possibly associated to changes in their working conditions. Data suggests that most educators were not prepared to face the technological challenges that came with the pandemic due to a lack of preparedness and experience in terms of digital competencies and remote learning pedagogical methods. ${ }^{21}$ For others, there is uncertainty on the impact of remote education on academic progress as it has been reported that students experience higher levels of psychological distress due to the pandemic. ${ }^{22}$ In this new context, the particularities of each student are now visible to some teachers and this can be a cause of stress and feelings of helplessness. ${ }^{23}$ Female teachers have also had to face the consequences of previously existing gender disparities concerning care and household chores that unequally augmented their demands and responsibilities. $^{24,25}$

Despite several countries allowing teachers and students to return face-to-face classes and other hybrid modalities, by 2021, Ecuador continues to implement online remote education to prevent new infections. Current data suggests that the pandemic has already had a toll on students' mental health. A study conducted with high school students between 14 and 18 years of age indicate that $16 \%$ of students presented symptoms compatible with major depression disorder. ${ }^{26}$ This percentage is alarming if compared to those found in studies conducted prior to the pandemic which indicate a prevalence of $6.2 \%$ of depression among students. ${ }^{27}$ Unfortunately, there is still limited information on the mental health condition of teachers in Ecuador.

To contribute to the growing literature on the effects of the COVID-19 pandemic on educators, this study turned its focus to the analysis of teachers' mental health and well-being. More specifically, this research aimed to assess the level of psychological distress, satisfaction with life, and perceived stress of Ecuadorian teachers. In addition, it sought to identify the specific actions and behaviors that teachers report using as coping strategies to maintain their emotional well-being and mental health. Studying these variables is important since stress and burnout are related to negative outcomes for teachers, students, and institutions $^{28}$ and given previous research indicating that teachers with high levels of distress are more likely to use negative coping strategies such as avoidance and throwing objects to reduce anger. ${ }^{29}$ Studying these variables may also help establish comparisons with findings from previous studies in pre-pandemic conditions, ${ }^{30-33}$ as well as those from other cultural settings during the pandemic. ${ }^{17,34}$ Online learning using ICTs is certainly not new; however, using these methods while living in a state of emergency 
and confinement is certainly novel. Thus, we believe this study will add valuable information to help develop future interventions that help restore and maintain educators' well-being and mental health.

\section{Materials and Methods}

\section{Study Design and Participants}

We conducted this study using a web-based cross-sectional survey that collected quantitative and qualitative information about the experiences of teachers in Ecuador in the context of the COVID-19 pandemic. Participants were asked to provide quantitative information about their psychological distress, satisfaction with life, and perceptions of stress. They were also given the option to provide qualitative information regarding the coping strategies they used to maintain their emotional well-being during the COVID-19 health emergency.

We used an online survey because, during the months of data collection, there were strict mobility restrictions in the country that limited our in person access to the population. Mail services in Ecuador are no longer used as the main form of communication, and teachers do not necessarily use these types of services. Most teachers started using ICTs to teach their lessons during the pandemic and thus were familiar with technological tools. Based on these factors, we concluded that using an online survey was the safest, fastest, and easiest way to recruit participants and collect their responses.

After approval from the Ethics Committee of Universidad de Las Américas, Ecuador (Ref: 20200611), we started recruiting participants using snowball sampling. The link to the survey was distributed using the personal and social networks of the research team members. The researchers also used institutional mailing lists to contact all faculty members at a private university. They also sent an invitation to the Ministry of Education of Ecuador and two private schools in Quito, Ecuador's capital, inviting their personnel and asking them to disseminate the invitation to other potential participants.

Participants were included in the sample if they were at least 18 years of age and were teaching in the country at the time of the COVID-19 pandemic. In addition, participants had to be teaching at any of the education levels that comprise the Ecuadorian Educational System (ie, preschool to postgraduate). Teachers interested in participating read the informed consent which contained the objectives, benefits, and risks of participation in the study. The participation was voluntary. The informed consent also included information to facilitate contact with the research team if any clarification was needed at any point of the study. Data collection was conducted between June and August 2020.

\section{Measures}

Data was collected using an online survey created and distributed through Microsoft Forms. The following information was collected:

\section{Sociodemographic Information}

This section included questions about participants' gender, age, and whether they had caregiving responsibilities of children under 11 years and/or adults over 65 years. Other questions were related to the education level at which participants taught at the time of the study (ie, teaching level), as well as pre- and post-pandemic experiences and training related to online teaching.

\section{Clinical Outcomes in Routine Evaluation-10 $(\text { CORE- I0) })^{35}$}

This brief self-report measure was used to screen general psychological distress. It includes items about depression, anxiety, physical problems, trauma, general functioning, and risk to oneself. Higher scores indicate higher levels of psychological distress. This measure has presented excellent psychometric properties $(\alpha=0.90)$ in a previous study in the UK. The Cronbach alpha in the present study was 0.85 with a $95 \%$ Confidence Interval $[82,87]$. In this study, we used the mean of the scores as the total score. As indicated by the authors, items two and three were reverse scored.

\section{Perceived Stress Scale (PSS) ${ }^{36}$}

This self-report scale was used to assess participants' perceived stress in the previous month. Higher scores indicate higher levels of perceived stress. The original version of the scale $^{36}$ as well as its translation to Spanish, ${ }^{37} \mathrm{~h}$ presented good psychometric properties. The 10-item Spanish version of the PSS (PSS-10) ${ }^{37}$ was used in the present study and scores evidenced high internal consistency with an alpha of 0.87 with a $95 \%$ Confidence Interval $[80,89]$. In this study, we used the sum of the scores as the total score, and items four, five, seven, and eight were reverse scored, based on authors' instructions. 


\section{Life Satisfaction (LS)}

To assess this variable, we included a single question developed by the UK Office of National Statistics: ${ }^{38}$ "Overall, how satisfied are you with your life?" Respondents were asked to respond using a scale that ranged from 0 ("not at all") to 10 ("completely").

\section{Coping Strategies}

This was a single optional open-ended question that required teachers to write the behaviors or strategies that they have used to cope and maintain their well-being during the COVID-19 health emergency.

\section{Data Analysis}

Descriptive statistics were conducted to characterize the sample. Frequencies and percentages were calculated for gender, participants with caregiving responsibilities, teaching level, pre-pandemic training in online teaching methods, prepandemic experience with online teaching, and postpandemic training in online teaching methods. Mean and standard deviations were calculated for the age and the scores of CORE-10, PSS-10, and LS measures. The associations of demographic and teaching characteristics were analyzed through the calculation of the mean difference and the corresponding bootstrapped $95 \%$ confidence interval (CI) of the level of each variable (gender, presence of caregiving responsibilities, teaching level, pre-pandemic online training, prepandemic teaching experience, post-pandemic training) in relation to each one of the three measures (CORE-10, PPS10, and LS). Means and standard deviations for each measure are presented. Also, the correlation between each measure was calculated using Spearman correlation. Bootstrapped $95 \%$ confidence intervals around sample statistics, including observed effect sizes, were reported rather than p-values, responding to guidelines that indicate that making inferences from p-values can be misleading. ${ }^{39}$ Analyses were conducted using $\mathrm{R}$ statistical software version 4.0.2. ${ }^{40}$

The qualitative information assessing participants' coping strategies was explored through deductive content analysis. ${ }^{41}$ Being an exploratory study, no analytical categories were established apriori. To ensure the quality of the analysis, credibility, dependability, confirmability, and transferability criteria ${ }^{42}$ were considered. For credibility and dependability, the first author obtained codes by analyzing each of the participants' responses using Microsoft Excel. Codes were later organized into categories (themes) using an Excel matrix that was later reviewed independently by each of the co-authors. At the end of the review process, discussions were held between the team members to reach a consensus and ensure validity. For higher dependability, the research process is explained, including the inclusion and exclusion criteria, as well as the contexts of the data collection. Regarding transferability, we are aware of the limitations of the generalization of the results due to its sample.

\section{Results}

In total, 394 participants met the inclusion criteria and completed the quantitative part of the study; of those, $320(81.2 \%)$ responded to the qualitative question regarding coping strategies. Of the total of 394 participants, $56.9 \%(n=224)$ were women and $42.6 \%(n=168)$ were men, 2 participants indicated gender as "other". The mean age was 43.4 years $(S D=9.89)$, ranging from 23 to 70 years. More than half of the participants $(53.6 \%, n=211)$ declared to take care of children under 11 years and/or adults over 65 years. The mean level of distress measured by the CORE-10 was $0.99(S D=0.62)$, the mean level of perceived stress measured by the PSS-10 was $13.0(S D=$ $6.8)$, and the mean life satisfaction was $8.23(S D=1.39)$. Most of the participants $(89.1 \%, n=351)$ were teaching in higher education (undergraduate and graduate programs). Around half of the participants $(50.3 \%, n=198)$ indicated having taught online courses before the COVID-19 pandemic and $63.5 \%(n=250)$ declared having received online education training prior to the pandemic. Most of the participants also indicated receiving training regarding online teaching methods during the pandemic $(77.9 \%$, $n=307)$.

\section{Sociodemographic Variables Related to Psychological Distress, Perceived Stress, and Life Satisfaction}

When comparing scores of the measures by gender, significant differences were identified only for the PSS total scores with $95 \%$ CI of the mean difference between the scores not containing zero. Women presented greater levels of perceived stress than men. Age was significantly and negatively correlated with the CORE-10 scores $\left(r_{s}=-0.22,95 \% \mathrm{CI}\right.$ $[-0.32,-0.12])$ and PSS scores $\left(r_{s}=-0.29,95 \%\right.$ CI $[-0.38$, $-0.20])$, while it was positively correlated with $\operatorname{LS}\left(r_{s}=0.18\right.$, 95\% CI [0.008, 0.27]). Despite significant p-values, the strength of the correlations was small. Regarding caregiving responsibilities, differences were identified for CORE-10 scores and PSS scores. Those having caregiving responsibilities presented greater levels of psychological distress and perceived stress than those who do not have them. Mean, 


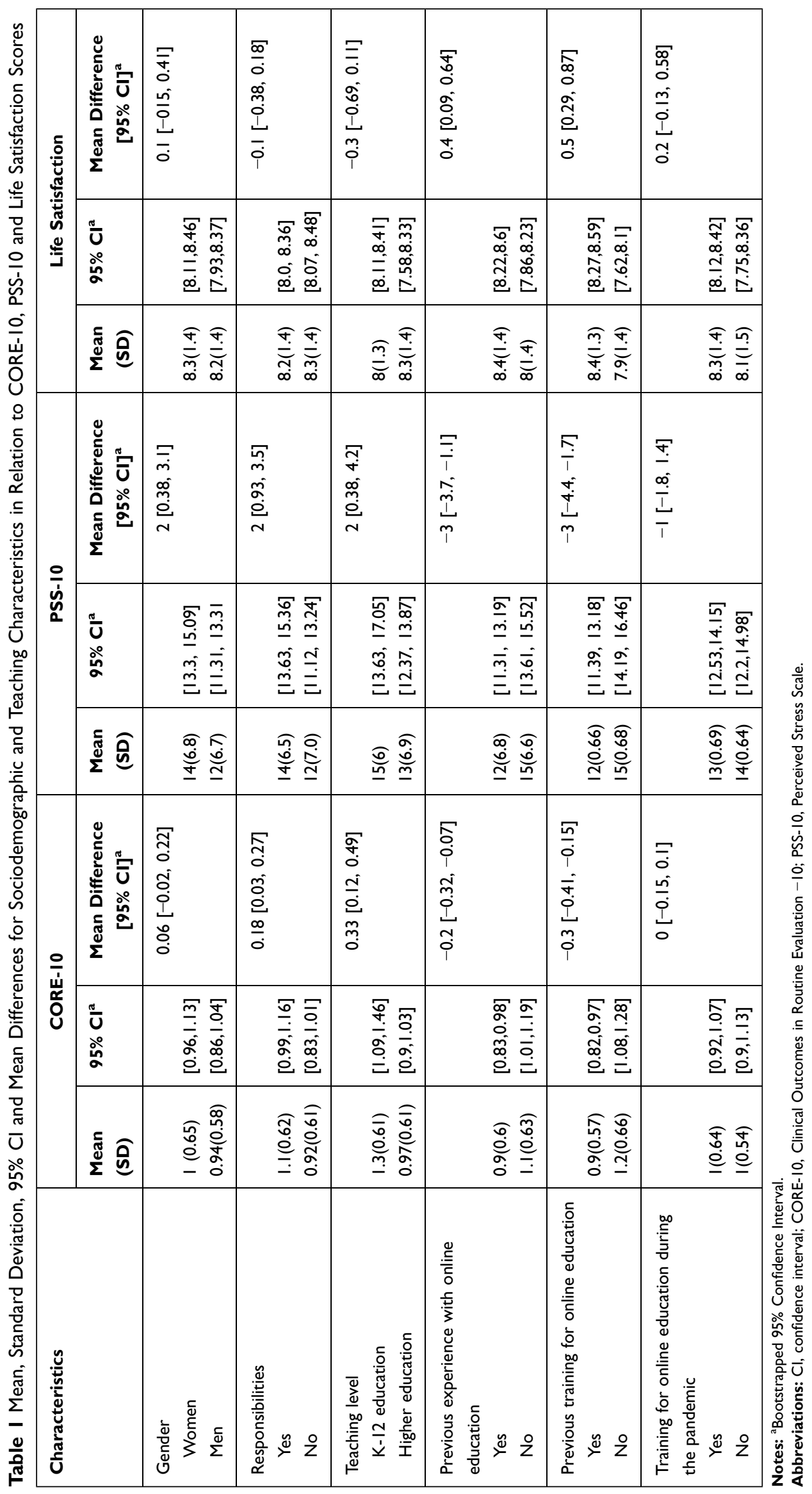


standard deviations, 95\% CI and mean difference of each characteristic in relation to CORE-10, PSS, and LS scores are presented in Table 1 .

Teaching Variables Related to Psychological Distress, Perceived Stress, and Life Satisfaction

Results in Table 1 also show significant differences in CORE-10 scores and PSS scores based on teaching levels. K-12 teachers (elementary and high school teachers) presented higher levels of psychological distress and perceived stress than college teachers. No significant differences were found concerning life satisfaction. Regarding pre-pandemic online education experience and training, significant differences were found for the three measures. Participants with pre-pandemic online teaching experiences presented lower levels of psychological distress and perceived stress and greater levels of life satisfaction than teachers who had not had that experience before the COVID-19 pandemic. A similar pattern was found in relation to pre-pandemic training. Finally, regarding training during the pandemic, no significant differences were found in any of the three studied measures.

\section{Coping Strategies}

Results indicated a wide variety of strategies that teachers used during the health emergency to maintain their emotional well-being. Table 2 summarizes the seven categories and 17 codes found in the analysis, with their respective definition. Table 2 also presents the number of participants that mentioned each code. The main categories were 1) social support, 2) healthy living, 3) leisure activities, 4) mental health promotion, 5) work and study activities, 6) spiritual activities, and 7) avoidance activities.

As can be seen in Table 2, social support was the most frequently used strategy among participants. The activities within this category included seeking and providing support by sharing with family and friends to maintain active and ongoing contact with them. The second most frequently mentioned strategy included activities directed at maintaining and improving participants' physical health. Within this category, we found responses that included exercising, practicing yoga, having a healthy diet, and maintaining daily routines.

The third most frequently mentioned category involved leisure activities. This category included a variety of activities such as watching movies, reading, playing music, knitting, family recreation, and hobbies. The code "other" was also included to encompass activities such as "helping around the house," "drinking tea" or "not going out." The fourth category, that is, mental health promotion, included activities related to

Table 2 Categories and Codes of Coping Strategies

\begin{tabular}{|c|c|c|}
\hline Category & Definition & Codes (n) \\
\hline Social support & Activities to create or maintain relationships with other people. & Social support (I89) \\
\hline Healthy living & Activities focused on maintaining physical health. & $\begin{array}{l}\text { Physical activity ( } 137) \\
\text { Health-related habits }(38) \\
\text { Organizing and scheduling (2I) }\end{array}$ \\
\hline Leisure activities & $\begin{array}{l}\text { Leisure-time activities that show no direct intent to develop a new skill or } \\
\text { learning. }\end{array}$ & $\begin{array}{l}\text { Leisure activities (166) } \\
\text { Other (32) }\end{array}$ \\
\hline $\begin{array}{l}\text { Mental health } \\
\text { promotion }\end{array}$ & Activities focused on maintaining emotional well-being and promoting self-care. & $\begin{array}{l}\text { Psycho-emotional activities (33) } \\
\text { Attitude (80) } \\
\text { Meditation (47) } \\
\text { Rationalization (18) } \\
\text { News avoidance (15) } \\
\text { Professional support (9) }\end{array}$ \\
\hline Work and study & $\begin{array}{l}\text { Activities focused on professional and/or academic growth that demonstrate } \\
\text { direct intent to develop a new skill or ability. }\end{array}$ & $\begin{array}{l}\text { Work-related (43) } \\
\text { Study-related (35) }\end{array}$ \\
\hline Spiritual activities & $\begin{array}{l}\text { Activities aligned with spirituality and/or religious rites, including the enjoyment } \\
\text { of contact with nature. }\end{array}$ & $\begin{array}{l}\text { Spirituality and religiously oriented (48) } \\
\text { Nature (20) }\end{array}$ \\
\hline Avoidance activities & Various activities with the explicit purpose of keeping busy. & Busy mind (28) \\
\hline
\end{tabular}


maintaining and promoting participants' psychological well-being, mental health, and self-care. Some strategies mentioned within this category were crying, talking about emotions and problems, focusing on oneself, thinking positively, having patience, laughing, being grateful, meditating, rationalizing, not watching the news, and following treatment with a psychologist or psychiatrist.

The work and study category included activities related to professional growth. Among these, "working" or "studying" were mentioned, in addition to other statements such as "distracting myself by preparing lessons or talking with the students" and "looking for new information related to the subjects I teach" or "following online courses on different topics." Participants also mentioned using spiritual strategies as ways to find meaning in life, and other religiously oriented strategies such as praying or reinforcing their beliefs in God to cope with the situation. Other participants also commented engaging in activities to connect with nature and their pets; these were included under the category of spiritual activities due to their meaningful sense of connection with the environment and other living creatures. Finally, participants reported using strategies that were coded as avoidant. Responses within this category included statements such as "keeping myself busy" and "keeping my mind occupied".

\section{Discussion}

Teaching is an essential task that had to carry despite the COVID-19 pandemic. The closure of educational institutions, the adoption of remote online education, and other factors including teachers' technological illiteracy ${ }^{21}$ and students' increased psychosocial and educational demands, ${ }^{43}$ had a potential toll on teachers' mental health. Given the novelty of this pandemic, and the limited research in Latin American countries, this study assessed teachers' mental health as well as the coping strategies of Ecuadorian teachers. We believe that research in this area could help design future strategies to actively support teachers' self-care and emotional processing of the pandemic. Helping teachers maintain their well-being will help them work more effectively with students and their families. Focusing on teachers, and closely examining the series of factors associated with their mental health, will also help raise awareness and actions to reduce the series of inequalities that the COVID-19 pandemic has shown across many countries in the world.

\section{Psychological Distress, Perceived Stress, and Life Satisfaction}

Our results indicate that psychological distress and perceived stress levels were lower than those reported in other studies. The mean level of psychological distress in our study was $0.99(S D=0.62)$, which is slightly lower than the general psychological distress cut-off score of 1.1 reported by Barkham et al. ${ }^{35}$ before the pandemic and the mean of 1.05 reported during the pandemic in Brazil with one of the CORE system measures. ${ }^{44}$ The perceived stress score was lower $(M=13, S D=6.8)$ than the scores reported by Pieh, Budimir, and Probst ${ }^{45}$ in a study conducted in Austria with the general population during the COVID-19 lockdown $(M=15.98, S D=7.47)$. In addition, life satisfaction was high in our sample.

A closer inspection of our results indicates that several sociodemographic characteristics were associated with the assessed variables. Age was significantly correlated with all three variables. It was negatively correlated with CORE-10 and PSS-10 perceived scores and positively correlated with LS scores, indicating that younger participants were more stressed, had greater levels of psychological distress, and less life satisfaction than older participants. These results are similar to other studies conducted during the pandemic which indicate that the younger adult population present greater levels of depression, anxiety, and distress. ${ }^{19,45}$ As in our study, research with Spanish ${ }^{46}$ and Philippine ${ }^{47}$ samples have shown that younger participants present significantly higher levels of stress than participants older than 50 years. However, in other studies conducted with participants from China, ${ }^{22,46,48}$ Poland $^{47}$ and Iran $^{49}$ the presence of a relationship between age and levels of stress has not been evident.

In our study, we found significant differences between men and women in their levels of perceived stress. In contrast, no differences were found in the CORE-10 nor the LS scores. Similar to the studies conducted by Klapproth et $\mathrm{al}^{17}$ in Germany, Lizana et $\mathrm{al}^{18}$ in Chile, and Saldívar-Garduño et $\mathrm{al}^{25}$ in Mexico, women in our study reported greater levels of perceived stress than men. Gender differences in the stress levels have also been reported in studies carried out in Austria, ${ }^{45}$ China, ${ }^{22}$ Poland, ${ }^{48}$ and the Philippines, ${ }^{47}$ in which women presented higher levels of stress than men. The presence of gender differences, in our study, might be explained due to gender roles and unequal domestic task distribution. 
Participants who reported being responsible and taking care of children and/or older adults also presented higher levels of distress and perceived stress than those who do not have these responsibilities. These findings are consistent with those indicating that work-family conflict has intensified among women due to the adoption of mandatory telework while facing the consequences of living in an emergency state caused by the pandemic.

We also studied the relation of stress, psychological distress, and life satisfaction with several teaching-related variables that might be relevant to describe possible impacts of online education. In our sample, most of the responses came from higher education teachers (89.1\%); however, when comparing them with K-12 teachers, we found that the latter were experiencing greater levels of perceived stress and psychological distress. This is probably explained by the job conditions and characteristics of K-12 teachers, such as the age of their students, the illiteracy of teachers on the usage of the online education methods and tools, students' lack of technological skills, and the fact that they must interact with parents.

Regarding online teaching, as expected, participants with pre-pandemic experience and training in online teaching methods reported lower levels of psychological distress, perceived stress and greater levels of life satisfaction. We were surprised by the high number of participants who reported having done online teaching $(50.3 \%)$ and received training $(63.5 \%)$ before the pandemic. These results might reflect a general interest in online education and innovative teaching and learning methods, even before the emergency was declared. These results might also be explained by the fact that most participants were higher education teachers, for whom the use of ICTs resources (eg, virtual classrooms) are mandatory, especially among those in private institutions. Another possible explanation is that online teaching was not unfamiliar for most teachers of this sample because, in October 2019, Ecuador experienced a lockdown due to violent social protests that resulted in an emergency scenario in which online teaching was adopted for seven days.

\section{Coping Strategies}

The qualitative section of the study analyzed the strategies that teachers used as ways to maintain their emotional well-being and mental health during the pandemic. Our results are presented in separate codes and categories to facilitate comprehension; however, it must be acknowledged that many of the strategies used in our sample were, in many cases, related to more than one category. For example, "being thankful" may represent an attitude towards life as well as the practice of spirituality or meditation. Similarly, "exercising as a family" may be linked to physical activity as well as social companionship.

Our results indicate that most teachers used more than one coping strategy and the three most frequently reported strategies were social support, physical activity (exercise), and leisure activities. These results differ from those in another study ${ }^{50}$ carried out with language teachers during the COVID-19 pandemic which show that the three most frequent coping strategies are acceptance, advanced planning, and re-framing. ${ }^{50}$ One explanation for this difference could be the data collection method; in MacIntryre et al's, study the Brief-COPE inventory was used using a set of pre-defined categories. However, based on the existing critiques toward quantitative approaches on coping, ${ }^{51}$ in this study, we decided to ask teachers to openly report the coping strategies they used during the health emergency.

It has been previously seen that burnout is negatively related to positive or task-oriented coping strategies that aim to limit or solve the stressful situation, and that it has no relationship with negative coping, such as avoidant strategies. ${ }^{52}$ Thus, the activities reported by most of the teachers in this study may be effective for burnout prevention (eg, learn a new task while at home, exercise, time management with a to-do list). Also, many teachers maintain their emotional well-being through activities directly related to work and improving their teaching quality. These activities could be a form of problem-solving, which has been negatively related to stress. ${ }^{29}$ This may be because, in this context, teaching-learning experiences must be carefully designed in such a way that they do not deepen structural inequalities in education. ${ }^{43}$ Spending time working and studying may also be relevant in a time in which career changes are expected as ways to cope with economic burdens and limitations. Institutions should pay attention to people who disengage and suggest other strategies to promote their well-being.

The results of this study support previous recommendations to provide personal and material resources, improve the digital skills of teachers and students, ${ }^{53}$ prepare the educational community psychologically and emotionally with resources, create policies that guarantee socioemotional stability, and strengthen teaching skills and support. ${ }^{54}$ Results are also in line with previous research that indicates that starting and maintaining hobbies is related to better mental health and fewer symptoms 
of anxiety and depression. ${ }^{55-57}$ School and system policies also affect teachers' stress ${ }^{28}$ and could either facilitate or complicate their coping. Based on our results, we believe that educational institutions could help develop strategies that use social support, physical exercising, and leisure activities to help them cope with the series of stressors associated with the pandemic. For example, educational institutions could promote virtual workshops to facilitate physical exercise, social connection, and leisure activities courses. These kinds of initiatives could be shared with friends, family members and peers to promote social support, which has been found to be effective promoting wellbeing. ${ }^{58}$

Interestingly, only one participant explicitly mentioned the use of online social networks as a coping strategy. Online sites such as Facebook or Twitter may be a source of information, but they may also be a source of stress and fake news. Thus, we believe that future interventions directed at teachers could consider using other media such as radio, television, podcasts, as well as other applications such as Zoom or Teams, to share useful information and offer people strategies to improve their mental health and cope with the current health situation. Interventions to prevent teacher stress should be adapted according to the educational level and type of center. Research shows that the type of coping strategies used varies according to the teaching level; for example, compared to secondary education teachers, pre-school and primary school teachers use more rational planning when facing student behavior problems and less pessimistic passivity when dealing with work overload. ${ }^{59}$ Our results partially support these findings. Although most of the strategies were used by teachers regardless of any sociodemographic characteristics, the strategy "rationalization" was mentioned only by higher education teachers. However, this result must be interpreted cautiously, given the composition of our sample.

\section{Limitations}

Overall, our results help understand the mental health state of Ecuadorian teachers during the pandemic; however, some limitations must be acknowledged. First, given the nature of this descriptive study, no causal interpretation can be drawn from our data. Also, our results must be considered with caution as most of the participants were higher education teachers, and data was not analyzed based on their institutions' characteristics (eg, public vs private, urban vs rural). It seems likely that the situation of teachers working in K-12 settings, and those in rural areas, are not the same, as they must face low access to ICTs. Moreover, this study used a snowball sampling strategy using an online survey. Thus, we may have an overrepresentation of technology-savvy participants with high access to the internet, limiting our capacities to generalize our results to the general population of educators.

\section{Conclusions}

Despite its limitations, this study presents a snapshot of the psychological distress, perceived stress, life satisfaction, and coping strategies reported by teachers in Ecuador during the COVID-19 pandemic. These results provide ideas for specific actions that can be promoted in all educational settings. This study calls attention to the need to further explore teachers' experiences concerning the pandemic and the importance of providing institutional support to enable well-being. The support can include psychological interventions using ICTs ${ }^{60,61}$ which have been used in other countries to reduce psychological distress.

Future studies must attend work-family conflicts, as our results indicate that teachers with caregiving responsibilities experience more psychological distress and perceived stress than those who do not have those responsibilities. Future studies could also gather information about teachers' mental health in samples with different sociodemographic characteristics. Additionally, future research could explore individual, work, and family conditions associated with the adoption of specific coping strategies and the experience of certain symptoms of discomfort and psychological stress.

The COVID-19 pandemic is evolving, and other challenges seem ahead. Future research might include efforts to understand the perceptions and willingness of teachers to get vaccinated against COVID- $19^{62}$ and the psychological impact of returning to face-to-face teaching which, in countries such as Spain, has already increased educators' discomfort. ${ }^{63}$ Providing further information on the COVID-19 pandemic is highly needed to get a wider picture of today's "new normal" education and to develop supportive strategies to enhance educators' well-being in future pandemics or emergency confinements. 


\section{Abbreviations}

CI, confidence interval; CORE-10, Clinical Outcomes in Routine Evaluation-10; COVID-19, Coronavirus disease 2019; ICTs, Information and Communication Technologies; PSS-10, Perceived Stress Scale -10 .

\section{Data Sharing Statement}

The data that support the findings of this study are available on request from the corresponding author, CP.

\section{Ethics Approval and Informed Consent}

The study was carried out in accordance with the Declaration of Helsinki. The protocol of the study was approved by the Ethics Committee of the Universidad de Las Américas, Ecuador (Ref: 2020-0611). Participation in the study was entirely voluntary with no monetary incentives nor compensation for the participants. All teachers interested in participating read the informed consent which contained the objectives, benefits, and risks of participation; those who agreed to participate in the study gave their informed consent, accepting to continue with the survey.

\section{Acknowledgments}

We would like to show our appreciation to all the teachers who continue to seek ways to improve society through education.

\section{Author Contributions}

All authors made significant contributions to the work reported, including the conception, study design, execution, acquisition of data, analysis, and interpretation; furthermore, they took part in drafting, revising, or critically reviewing the article; gave final approval of the version to be published; have agreed on the journal to which the article has been submitted, and agree to be accountable for all aspects of the work.

\section{Disclosure}

The authors report no conflicts of interest in this work.

\section{References}

1. World Health Organization. Coronavirus disease 2019. Coronavirus disease (COVID-19) outbreak situation; 2020. Available from: https:// www.who.int/emergencies/diseases/novel-coronavirus-2019. Accessed June 22, 2021.

2. Sahu P. Closure of universities due to Coronavirus disease 2019 (COVID-19): impact on education and mental health of students and academic staff. Cureus. 2020;2019(4):4-9. doi:10.7759/cureus.7541
3. Ramij M, Sultana A. Preparedness of online classes in developing countries amid COVID-19 outbreak: a perspective from Bangladesh. SSRN Electron J. 2020. doi:10.2139/ssrn.3638718

4. Purwanto A, Asbari M, Fahlevi M, et al. Impact of work from home (WFH) on Indonesian teachers performance during the Covid-19 pandemic: an exploratory study. Int J Adv Sci Technol. 2020;29 (5):6235-6244.

5. UNICEF. La falta de igualdad en el acceso a la educación a distancia en el contexto de la COVID-19 podría agravar la crisis mundial del aprendizaje [Inequality in the acces of education during COVID-19 pandemic might aggravate global learnig crisis]; 2020. Available from: https://www.unicef.org/es/comunicados-prensa/falta-igualdadacceso-educacion-distancia-podria-agravar-crisis-aprendizaje. Accessed June 22, 2021.

6. González-Sanguino C, Ausín B, Castellanos MÁ, et al. Mental health consequences during the initial stage of the 2020 Coronavirus pandemic (COVID-19) in Spain. Brain Behav Immun. 2020;87 (May):172-176. doi:10.1016/j.bbi.2020.05.040

7. Xiong J, Lipsitz O, Nasri F, et al. Impact of COVID-19 pandemic on mental health in the general population: a systematic review. $J$ Affect Disord. 2020;277:55-64. doi:10.1016/j.jad.2020.08.001

8. Le HT, Lai AJX, Sun J, et al. Anxiety and depression among people under the nationwide partial lockdown in Vietnam. Front Public Health. 2020;8(October):1-8. doi:10.3389/fpubh.2020.589 359

9. Wang C, Chudzicka-Czupała A, Tee ML, et al. A chain mediation model on COVID-19 symptoms and mental health outcomes in Americans, Asians and Europeans. Sci Rep. 2021;11(1). doi:10.1038/s41598-021-85943-7

10. Wang C, Tee M, Roy AE, et al. The impact of COVID-19 pandemic on physical and mental health of Asians: a study of seven middle-income countries in Asia. PLoS One. 2021;16 (Febuary):1-20. doi:10.1371/journal.pone.0246824

11. Tran BX, Nguyen HT, Le HT, et al. Impact of COVID-19 on economic well-being and quality of life of the Vietnamese during the national social distancing. Front Psychol. 2020;11(September):1-9. doi:10.3389/fpsyg.2020.565153

12. Paz C, Mascialino G, Adana-Díaz L, et al. Behavioral and sociodemographic predictors of anxiety and depression in patients under epidemiological surveillance for COVID-19 in Ecuador. PLoS One. 2020;15(9):e0240008. doi:10.1371/journal.pone.0240008

13. Paz C, Mascialino G, Adana-Díaz L, et al. Anxiety and depression in patients with confirmed and suspected COVID -19 in Ecuador. Psychiatry Clin Neurosci. 2020;74:pcn.13106. doi:10.1111/pcn.13106

14. Mucci F, Mucci N, Diolaiuti F. Lockdown and isolation: psychological aspects of COVID-19 pandemic in the general population. Clin Neuropsychiatr. 2020;17(2):63-64. doi:10.36131/CN20200205

15. Samaniego A, Urzúa A, Buenahora M, Vera-Villarroel P. Sintomatología asociada a trastornos de salud mental en trabajadores sanitarios en Paraguay: efecto Covid-19 [Associated symptoms to mental health disorders in health-workers in Paraguay: the effects of Covid-19]. Rev Interam Psicol J Psychol. 2020;54(1):e1298. doi:10.30849/ripijp.v54i1.1298

16. Wang C, Pan R, Wan X, et al. A longitudinal study on the mental health of general population during the COVID-19 epidemic in China. Brain Behav Immun. 2020;87(April):40-48. doi:10.1016/j. bbi.2020.04.028

17. Klapproth F, Federkeil L, Heinschke F, Jungmann T. Teachers experiences of stress and their coping strategies during COVID - 19 induced distance teaching. J Pedagog Res. 2020;4(4):444-452. doi:10.33902/JPR.2020062805

18. Lizana PA, Vega-Fernadez G, Gomez-Bruton A, Leyton B, Lera L. Impact of the COVID-19 pandemic on teacher quality of life: a longitudinal study from before and during the health crisis. Int J Environ Res Public Health. 2021;18:3764. doi:10.3390/ ijerph18073764 
19. Huang Y, Zhao N. Generalized anxiety disorder, depressive symptoms and sleep quality during COVID-19 outbreak in China: a web-based cross-sectional survey. Psychiatry Res. 2020;288:112954. doi:10.1016/j.psychres.2020.112954

20. Allen R, Jerrim J, Sims S. How Did the Early Stages of the COVID19 Pandemic Affect Teacher Wellbeing? Centre for Education Policy and Equalising Opportunities (CEPEO) Working Paper; 2020.

21. Fernández Cruz FJ, Fernández Díaz MJ, Rodríguez Mantilla JM. El proceso de integración y uso pedagógico de las TIC en los Centros Educativos Madrileños [The integration process and pedagogical use of ICT in Educational Centers from Madrid]. Educ XX1. 2018;21 (2):395-416. doi:10.5944/educXX1.17907

22. Wang C, Pan R, Wan X, et al. Immediate psychological responses and associated factors during the initial stage of the 2019 coronavirus disease (COVID-19) epidemic among the general population in China. Int J Environ Res Public Health. 2020;17(5). doi:10.3390/ ijerph17051729

23. Anderson R, Bousselot T, Katz-Buoincontro J, Todd J. Generating buoyancy in a sea of uncertainty: teachers creativity and well-being during the COVID-19 pandemic. Front Psychol. 2020;11:614774. doi:10.3389/fpsyg.2020.614774

24. Castellanos-Torres E, Tomás Mateos J, Chilet-Rosell E. COVID-19 en clave de género. Gac Sanit. 2020;34(5):419-421. doi:10.1016/j. gaceta.2020.04.007

25. Saldívar-Garduño A, Ramírez-Gómez KE. Salud mental, género y enseñanza remota durante el confinamiento por el COVID-19 en México. Persona. 2020;23(023(2)):11-40. doi:10.26439/persona2020.n023(2).5011

26. Asanov I, Flores F, McKenzie DJ, Mensmann M, Schulte M. Remote-learning, time-use, and mental health of ecuadorian high-school studentsduring the Covid-19 quarantine. World Dev. 2020 .

27. Torres C, Otero P, Bustamante B, Blanco V, Díaz O, Vázquez F. Mental health problems and related factors in Ecuadorian college students. Int $J$ Environ Res Public Health. 2017;14(5):530. doi:10.3390/ijerph14050530

28. Herman KC, Reinke WM, Eddy CL. Advances in understanding and intervening in teacher stress and coping: the coping-competencecontext theory. $J$ Sch Psychol. 2020;78:69-74. doi:10.1016/j. jsp.2020.01.001

29. Austin V, Shah S, Muncer S. Teacher stress and coping strategies used to reduce stress. Occup Ther Int. 2005;12(2):63-80. doi:10.1002/oti.16

30. Martínez Ramón JP. Cómo se defiende el profesorado de secundaria del estrés: burnout y estrategias de afrontamiento [How high school teachers deal with stress: burnout and coping strategies]. J Work Organ Psychol. 2015;31:1-9.

31. Antoniou A, Ploumpi A, Ntalla M. Occupational stress and profesional burnout in teachers of primary and secondary education: the role of coping strategies. Psychology. 2013;4(3):329-355. doi:10. 4236/psych.2013.43A051

32. Acosta M, Burguillos A. Estrés y burnout en profesores de primaria y secundaria de Huelva: las estrategias de afrontamiento como factor de protección [Stress and burnout in primary and secondary teachers from Huelva: coping strategies as protective factors]. Int J Dev Educ Psychol Rev Psicol. 2014;4(1):303-309. doi:10.17060/ijodaep.2014.n1.v4616

33. Cháidez Nevárez J, Barraza Macías A. Afrontamiento al estrés y su relación con el tipo de jornada laboral en docentes de educación primaria [Coping with stress and its realtionship with the type of workday in prymary school teachers. Inf Psicológicos. 2018;18 (2):63-75. doi:10.18566/nfpsic.v18n2a04

34. Mohamad Nasri N, Husnin H, Diyana Mahmud S, Halim L. Mitigating the COVID-19 pandemic: a snapshot from Malaysia into the coping strategies for pre-service teachers' education. J Educ Teach. 2020;46(4):546-553. doi:10.1080/02607476.2020.1802582
35. Barkham M, Bewick B, Mullin T, et al. The CORE-10: a short measure of psychological distress for routine use in the psychological therapies. Couns Psychother Res. 2013;13(1):3-13. doi:10.1080/ 14733145.2012.729069

36. Cohen S, Kamarck T, Mermelstein R. A global measure of perceived stress. J Health Soc Behav. 1983;24(4):385-396. doi:10.2307/ 2136404

37. Remor E. Psychometric properties of a European Spanish version of the Perceived Stress Scale (PSS). Span J Psychol. 2006;9(1):86-93. doi:10.1017/S1138741600006004

38. UK Office of National Statistics. Analysis of experimental subjective well-being data from the annual population survey. 2011.

39. Klein D. Beyond significance testing: reforming data analysis methods in behavioral research. Am J Psychiatry. 2005;162(3):643-a-644. doi:10.1176/appi.ajp.162.3.643-a

40. R Core Team. R: a language and environment for statistical computing; 2020. Available from: http://www.r-project.org/. Accessed June 22, 2021.

41. Nowell LS, Norris JM, White DE, Moules NJ. Thematic analysis. Int J Qual Methods. 2017;16(1):160940691773384. doi:10.1177/ 1609406917733847

42. Lincoln Y, Guba EG. Naturalistic Inquiry. Sage; 1985.

43. Kaden U. COVID-19 school closure-related changes to the professional life of a K-12 teacher. Educ Sci. 2020;10(6):165. doi:10.3390/ educsci10060165

44. Serralta FB, Zibetti MR, Evans C. Psychological Distress of University Workers during COVID-19 Pandemic in Brazil. Int $J$ Environ Res Public Health. 2020;17(20):8520. doi:10.3390/ ijerph17228520

45. Pieh C, Budimir S, Probst T. The effect of age, gender, income, work, and physical activity on mental health during coronavirus disease (COVID-19) lockdown in Austria. $J$ Psychosom Res. 2020;136:110186. doi:10.1016/j.jpsychores.2020.110186

46. Wang C, López-Núñez MI, Pan R, et al. The impact of 2019 coronavirus disease (COVID-19) pandemic on physical and mental health: a comparison between China and Spain. JMIR Form Res. 2021;5. doi:10.2196/27818

47. Tee ML, Tee CA, Anlacan JP, et al. Psychological impact of COVID-19 pandemic in the Philippines. J Affect Disord. 2020;277 (January):379-391. doi:10.1016/j.jad.2020.08.043

48. Wang C, Chudzicka-Czupała A, Grabowski D, et al. The association between physical and mental health and face mask use during the COVID-19 pandemic: a comparison of two countries with different views and practices. Front Psychiatry. 2020;11:569981. doi:10.3389/ fpsyt.2020.569981

49. Wang C, Fardin MA, Shirazi M, et al. Mental health of the general population during the 2019 coronavirus disease (COVID-19) pandemic: a tale of two developing countries. Psychiatry Int. 2021;2:71-84. doi:10.3390/psychiatryint2010006

50. MacIntyre PD, Gregersen T, Mercer S. Language teachers' coping strategies during the Covid-19 conversion to online teaching: correlations with stress, wellbeing and negative emotions. System. 2020;94:102352. doi:10.1016/j.system.2020.102352

51. Oakland S, Ostell A. Measuring coping: a review and critique. Hum Relations. 1996;49(2):133-155. doi:10.1177/001872679604900201

52. García-Arroyo J, Osca Segovia A. Work overload and emotional exhaustion in university teachers: moderating effects of coping styles. Univ Psychol. 2019;18(2):1-12. doi:10.11144/Javeriana. upsy18-2.woee

53. Martínez-Pérez A, Lezcano-Barbero F. Percepción del impacto de la Covid-19 en los profesionales de la educación social que trabajan con menores [Perception of the impact of Covid-19 in high school professionals working with minors]. Rev Int Educ Para La Justicia Soc. 2020;9(3e):223-243. doi:10.15366/ riejs2020.9.3.012 
54. Peñate L. Todos somos importantes, pero el docente es imprescindible [We are all important, but teachers are essential]. Rev Int Educ Para La Justicia Soc. 2020;9(3):1-4.

55. Takeda F, Noguchi H, Monma T, Tamiya N. How possible do leisure and social activities impact mental health of middle-aged adults in Japan?: an evidence from a national longitudinal survey. PLoS One. 2015;10(10):e0139777. doi:10.1371/journal.pone.0139777

56. Fancourt D, Opher S, De Oliveira C. Fixed-effects analyses of time-varying associations between hobbies and depression in a longitudinal cohort study: support for social prescribing? Psychother Psychosom. 2020;89(2):111-113. doi:10.1159/000503571

57. Fullana M, Hidalgo-Mazzei D, Vieta E, Radua J. Coping behaviors associated with decreased anxiety and depressive symptoms during the COVID-19 pandemic and lockdown. J Affect Disord. 2020;275:80-81. doi:10.1016/j.jad.2020.06.027

58. Dias-Lacy SL, Guirguis RV. Challenges for new teachers and ways of coping with them. J Educ Learn. 2017;6(3):265. doi:10.5539/jel. v6n3p265

59. Gismero-González M, Bermejo L, Prieto M, García Mina A, Hernández V, Hernández V. Estrategias de afrontamiento cognitivo, autoeficacia y variables laborales. Orientaciones para prevenir el estrés docente [Cognitive coping strategies, self-efficacy and labor variables. Guidelines to prevente stress in teachers]. Acción Psicológica. 2012;9(2):87-96. doi:10.5944/ap.9.2.4107
60. Ho CS, Chee CY, Ho RC. Mental health strategies to combat the psychological impact of COVID-19 beyond paranoia and panic. Ann Acad Med Singapore. 2020;49(1):1-3.

61. Tran BX, Hoang MT, Vo LH, et al. Telemedicine in the COVID-19 pandemic: motivations for integrated, interconnected, and community-based health delivery in resource-scarce settings? Front Psychiatry. 2020;11(September):11-13. doi:10.3389/fpsyt.2020.56 4452

62. Chew NWS, Cheong C, Kong G, et al. An Asia-Pacific study on healthcare workers' perceptions of, and willingness to receive, the COVID-19 vaccination. Int $J$ Infect Dis. 2021;106:52-60. doi:10.1016/j.ijid.2021.03.069

63. Ozamiz-Etxebarria N, Berasategi Santxo N, Idoiaga Mondragon N, Dosil Santamaría M. The psychological state of teachers during the COVID-19 crisis: the challenge of returning to face-to-face teaching. Front Psychol. 2021;11:620718. doi:10.3389/fpsyg.2020.620718
Psychology Research and Behavior Management

\section{Publish your work in this journal}

Psychology Research and Behavior Management is an international, peer-reviewed, open access journal focusing on the science of psychology and its application in behavior management to develop improved outcomes in the clinical, educational, sports and business arenas. Specific topics covered in the journal include: Neuroscience, memory and decision making; Behavior modification and management; Clinical

\section{Dovepress}

applications; Business and sports performance management; Social and developmental studies; Animal studies. The manuscript management system is completely online and includes a very quick and fair peer-review system, which is all easy to use. Visit http://www. dovepress.com/testimonials.php to read real quotes from published authors. 